\title{
Recommendations of the Canadian Consensus Conference on Dementia - Dissemination, Implementation, and Evaluation of Impact
}

\author{
David B. Hogan, Penny Jennett, Susan Freter, Howard Bergman, \\ Howard Chertkow, Susan Gold, A. Mark Clarfield
}

\begin{abstract}
Background: Subsequent to the development of consensus statements on a clinical topic, it is vital to establish a plan for dissemination, implementation and evaluation of impact. Consensus statements can be used for both guiding continuing medical education (CME) and producing clinical practice guidelines (CPGs). Insufficient attention to dissemination can lead to a failure to change physician behaviour and improve patient outcomes. Methods: A plan to disseminate the conclusions of the Canadian Consensus Conference on Dementia (CCCD) was developed. This plan was based on a literature review of CME and CPGs. A Medline search was performed on the dissemination and evaluation of the 1989 Canadian Consensus Conference on the Assessment of Dementia (CCCAD) and other published guides for physicians on dementia care. CCCD dissemination that has occurred to date (June, 2000) was reviewed in this paper. Results: Lectures and unsolicited printed material are weak forms of CME. Small-group interactive CME that provides practice opportunities appears to be the most effective way to change physician behaviour. The ability of CPGs to change physician behaviour is uncertain. It appears that inadequate attention has been placed on CPG dissemination and implementation. The CCCAD had a modest impact on clinical practice in Canada. While dissemination of the conclusions of the CCCD has taken place, evaluation of the impact of the CCCD has yet to be done. Local initiatives utilizing the conclusions of the CCCD are on-going. Conclusions: Further work is needed on how to optimize the impact of consensus statements and CPGs. While dissemination of the CCCD has occurred, it is currently unknown whether it has led to any change in physician practices.
\end{abstract}

RÉSUMÉ: Recommandations de la Conférence canadienne de consensus sur la démence - Diffusion, application et évaluation de l'impact. Introduction: Suite à l'élaboration d'un consensus sur un sujet clinique, il est très important d'établir un plan pour la diffusion, l'application et l'évaluation de l'impact. Un énoncé consensuel peut être utilisé pour guider l'éducation médicale continue (ÉMC) et émettre des lignes directrices pour la pratique clinique (LDPC). Si on néglige la diffusion, on risque de ne pas réussir à modifier le comportement des médecins et l'issue pour les patients. Méthodes: Un plan pour la diffusion des conclusions de la Conférence canadienne de consensus sur la démence (CCCD) a été développé. Ce plan était basé sur une revue de la littérature sur l'ÉMC et les LDPC. Une recherche a été effectuée dans la banque de données Medline sur la diffusion et l'évaluation de la Conférence canadienne de consensus sur l'évaluation de la démence (CCCÉD) ainsi que sur la diffusion d'autres guides publiés à l'intention des médecins sur la prise en charge de la démence. La diffusion de la CCCD à date (juin 2000) est revue dans cet article. Résultats: Les conférences et les publications non sollicitées sont des moyens faibles d'ÉMC. L'ÉMC interactive en petits groupes qui fournit des occasion de pratique semble être la méthode la plus efficace pour changer le comportement des médecins. Le pouvoir des LDPC de modifier le comportement des médecins est incertain. Il semble qu'une attention insuffisante a été portée sur la diffusion et l'application des LDPC. La CCCD a eu un impact modeste sur la pratique clinique au Canada. Bien que les conclusions de la CCCD aient été diffusées, l'évaluation de l'impact de la CCCD n'a pas encore été faite. Des initiatives locales utilisant les conclusions de la CCCD sont en cours. Conclusions: On doit travailer davantage sur la façon d'optimiser l'impact des énoncés de consensus et des LDPC. Bien que la diffusion de la CCCD ait été faite, on ne sait pas si les pratiques des médecins ont changé.

Can. J. Neurol. Sci. 2001; 28: Suppl. 1 - S115-S121

The Canadian Consensus Conference on Dementia (CCCD) was held in Montreal (February 27 and 28, 2000) and led to the drafting of recommendations which reflected the collective opinion of the participants. ${ }^{1}$ Literature reviews, expert opinion, and group discussion were used to arrive at summary statements
From the Division of Geriatric Medicine (DBH), and the Office of Medical Education (PJ), University of Calgary, Calgary; the Division of Geriatric Medicine, Sir Mortimer B. Davis - Jewish General Hospital, McGill University, Montreal (SF, HB, HC, SG, AMC); and the Ministry of Health, Israel (AMC).

Reprint requests to: DBHogan, Health Sciences Centre, University of Calgary, 3330 Hospital Dr., NW, Calgary Alberta T2N 4N1 Canada 
which represented the majority (and current) opinion of the participants of the meeting. Details on how this was done are available elsewhere as are the consensus statements themselves. ${ }^{1}$ The format used was of a consensus conference without a jury using an ad hoc process. ${ }^{2,3}$ The principal goal of the CCCD was to develop consensus statements on which to base clinical practice guidelines (CPGs) for the recognition, assessment and management of dementing disorders. ${ }^{1}$ While it was felt that the statements could provide general direction to practicing physicians, ${ }^{4}$ they lacked the specificity required for CPGs. ${ }^{5}$ In the United Kingdom, recent CPGs for the management of depression in primary care have reflected the joint consensus statement produced by the Royal College of General Practitioners and the Royal College of Psychiatrists. ${ }^{6}$ It was hoped that a similar outcome would occur in Canada with CPGs on the assessment and management of dementia in primary medical care settings being based on the CCCD. It was also anticipated that the recommendations of the CCCD would inform continuing medical education (CME) programs designed to improve the knowledge and skills of primary care physicians in this area.

Clinical practice guidelines are systematically developed statements designed to assist the decision-making of practitioners and patients about appropriate health care for specific clinical circumstances. ${ }^{7}$ They can be seen as a means to describe what should be done. ${ }^{8}$ CPGs can be a tool to facilitate the dissemination and implementation of consensus statements CPGs make these statements operational. Interest in CPGs has increased over recent years. In 1994, the Canadian Medical Association (CMA) published a directory of Canadian CPGs which contained information on over 500 entries. ${ }^{9}$ While the number of CPGs produced over the last decade has been prodigious, considerably less effort has been expended on their dissemination, implementation, and evaluation. ${ }^{10}$

It is hoped that CPGs will improve patient care and outcomes by making decision-making more informed. Other potential benefits of CPGs include the education of practitioners, rationalizing the provision of health care services (thereby hopefully decreasing costs and improving utilization), forming a basis for practice review criteria (thereby enhancing audit and peer review), and reducing professional liability. ${ }^{11}$ A survey of Canadian physicians found that 52\% used CPGs at least monthly and over $50 \%$ strongly agreed that they are both a convenient source of advice and good educational tools. ${ }^{12}$ The user friendliness (e.g., short pamphlets, pocket cards) of CPGs was felt to be very important by $62 \%$ of respondents. The CMA's 1998 Physician Resource Questionnaire found that $80 \%$ of physicians use CPGs. ${ }^{13}$

In this article we briefly review effective CME methodologies and how CPGs should be developed. We examine the impact of the Canadian Consensus Conference on the Assessment of Dementia (CCCAD) held in 1989 and other published guides to dementia care. Finally, we look at what has been done and what is being proposed to disseminate and implement the recommendations of the CCCD.

\section{Effective Continuing Medical Education}

Much of the relevant information on how we can promote change in physician behaviour comes from the CME literature. ${ }^{14-}$ 25 Outreach visits (especially when combined with social marketing), interactive workshops that enhance active participation by allowing discussion and practice, use of opinion leaders, patient-mediated interventions, computer-based clinical decision support systems, and physician reminders are the methodologies which are more likely to lead to changes in physician performance. Short, lecture-style CME programs and unsolicited printed material do not appear to be effective in themselves. Audit with feedback has an intermediate impact. Combinations of two or more effective CME methodologies work better than single interventions. Attention should be placed on the specific educational needs of the learner and the barriers which may prevent the adoption of a change. Educational interventions tend to be, at most, moderately effective in changing physician behaviour with no "spill-over" effect on clinical problems not directly covered in the CME program.

\section{DEVELOPMENT OF GUIDELINES}

CPGs are linked to the evidence-based movement. The production of CPGs should ideally incorporate several components - identification of a clinical problem or area; collection and synthesis of data; development of a guideline statement; endorsement by sponsoring body(ies); dissemination; implementation; and, monitoring and evaluation of effect. ${ }^{14,15,26-30}$ We will not deal with the first three components in this background paper. It goes without saying that CPGs should be based on the best available data or they should not be disseminated. Consensus conferences are appropriate for use in the development of CPGs, particularly where the evidence is sparse. ${ }^{31}$

Endorsement: After the development of the guideline statement, the sponsoring body(ies) and/or other interested organizations should be requested to review and endorse the CPG. Endorsement by respected colleagues and/or major organizations was identified as very important by $78 \%$ and $62 \%$ of Canadian physicians respectively in deciding whether to adopt a CPG. ${ }^{12}$

Dissemination: Primary low-intensity dissemination is usually done by either publication (e.g., subsidized monographs/papers, journal articles) or oral presentations at conferences, lectures and teaching rounds. This form of dissemination is, at least superficially, relatively simple to organize. Much of the literature to date has been on the dissemination of research findings. ${ }^{32}$ The developers of CPGs must ensure that primary dissemination occurs. Guidelines must be presented in a manner that is both accessible and understandable to the target audience.

With primary dissemination, one is trying to have physicians reach the recognition/identification stage of change. Awareness of better practices would hopefully predispose a physician to change but for change to actually occur, generally one would also require enabling and/or reinforcing interventions.

Implementation and maintenance of change: To have clinicians actually change behaviour is a complex (and difficult) task. External forces, practice-related factors, and personal attributes all contribute to the change process. ${ }^{33}$ The competing demands placed on physicians raise particular issues - see 
Figure: Factors potentially influencing the assessment/management of cognition impairment by a primary care physician ${ }^{34}$

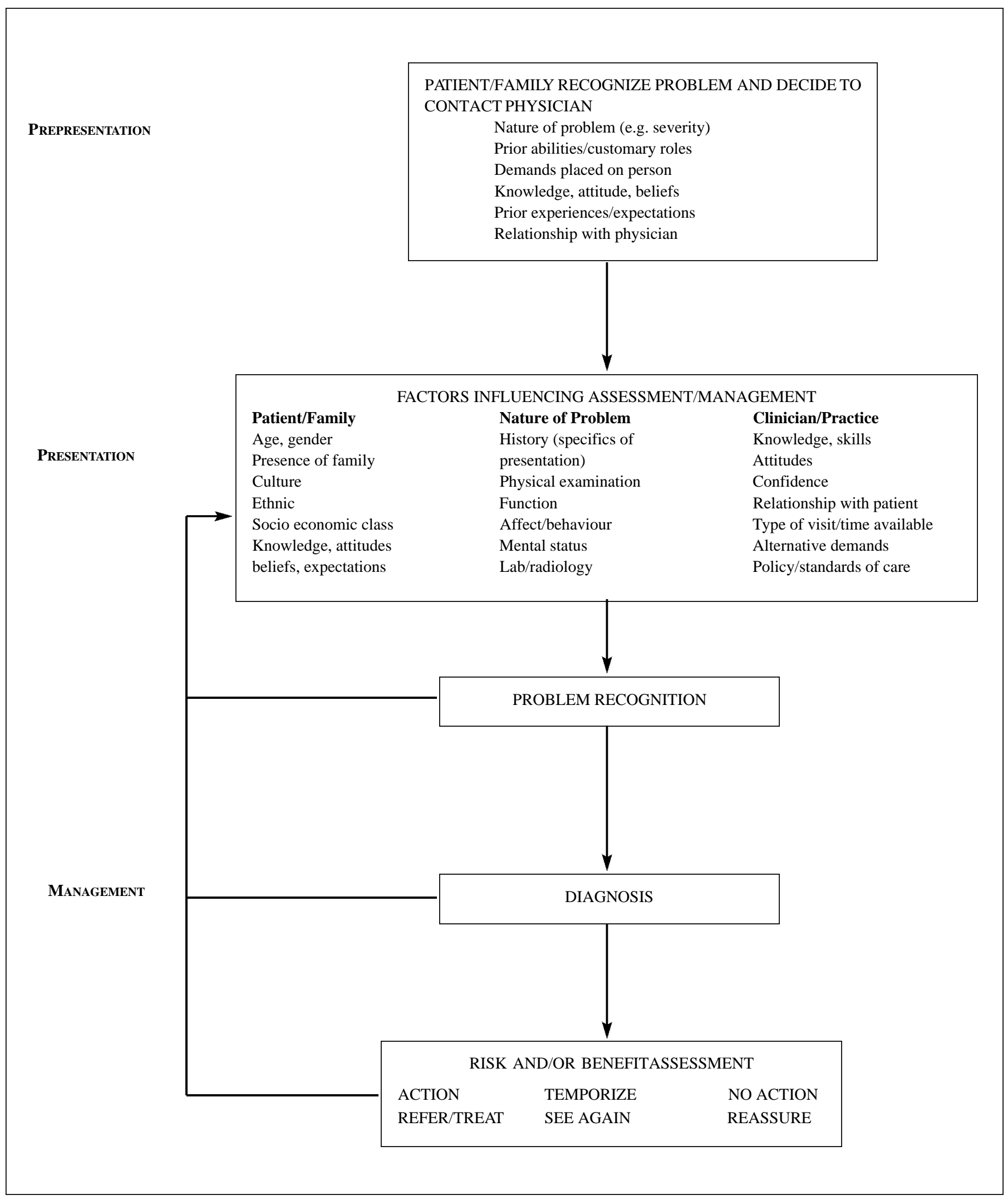


Figure. ${ }^{34}$ Only some of the factors noted in the Figure will be favorably influenced by greater knowledge in itself. Five features have been identified that influence the adoption of an innovation: its complexity; the relative advantage of the approach over existing practices and procedures; the opportunity to observe the innovation in use before adopting it; compatibility with similar products/procedures already in the professional's practice; and, the opportunity to try the innovation before adoption. $^{35}$

The literature on guideline adoption mirrors the CME literature. Lectures and unsolicited mailed materials generally fail to change physician behaviour. When coupled with enabling and reinforcing interventions, practice changes can occur. There appears to be the need for two stages in the dissemination/ adoption process - first a dissemination strategy which aims to inform as many clinicians as possible about the guidelines and second, an implementation strategy. ${ }^{15}$ "Buy-in" by practicing physicians is more likely if the development is done locally, there is targeted dissemination, and a well-thought out plan to enable and reinforce adoption is implemented. A recent report of a program to enhance physician adoption of influenza vaccination guidelines provides an example of a successful dissemination/adoption strategy. ${ }^{36}$ The primary intervention was a small-group consensus process where a physician expert presented the guidelines to invited physicians followed by a structured group discussion on how to implement. This culminated in a public commitment to adopt the guidelines. Vaccination rates went up in patients cared for by the intervention group as compared to those cared for by control physicians. A recent review of the effectiveness of CPGs concluded that there is little evidence that their use improves patient outcomes in primary care settings. ${ }^{37}$ Many of the older CPGs which were evaluated left much to be desired. Research on the effectiveness of CPGs is difficult to design let alone do. ${ }^{38}$ Common barriers to the adoption of CPGs include awareness, familiarity, agreement, self-efficacy, outcome expectancy, ability to overcome the inertia of previous practice, and external barriers to the recommendations. ${ }^{39}$

Monitoring/Evaluation: Prior to dissemination the guidelines themselves need to be examined by both the developers and potential users. ${ }^{38}$ This evaluation would include looking at the quality of the CPGs, their applicability and practicality of the guidelines within commonly encountered care settings. How they are utilized in "real world" environments and specifically whether they change the performance or behaviour of health care workers should be addressed (guidelines program evaluation). Aside from the quality and relevance of the CPGs, how they are disseminated and implemented will influence adoption by practitioners. This evaluation should be based on explicitly stated goals of the CPG. Process, outcome, and/or efficiency of care can be examined. A rigorous scientific evaluation would add to our fund of information and lead to the production of better CPGs. ${ }^{40}$

CPGs should be monitored by a responsible party after release. Post-dissemination problems will inevitably arise. Some body should assume responsibility to clarify ambiguous areas and correct errors of fact. Over time our knowledge base will change. CPGs will predictably require regular updating.

\section{Dissemination AND STUdies OF THE INITIAL CANAdian Consensus Conference on THE ASSESSMENT OF DEMENTIA}

The CCCAD took place in October of 1989. Thirty-eight experts from a variety of disciplines met over two days. Their consensus recommendations were directed at helping primary care physicians deal with the assessment of suspected dementia. A monograph as well as a summary of the deliberations were published and distributed to members of the CMA..$^{41,42}$ Copies of the monograph were also sent to relevant organizations, select members of the general public and the medical media. Participants were encouraged to present on aspects of the report. An approach to the assessment of dementia in the office setting based on the CCCAD was published in the Canadian Family Physician. $^{43}$ Most efforts to disseminate the consensus statements admittedly were not documented in the medical literature. The CCCAD was not noted in the "Directory of Canadian Clinical Practice Guidelines" $"$ nor was it listed on the CMACPG Infobase (http://www.cma.ca/cpgs/).

A Medline search (using "Canadian Consensus Conference on the Assessment of Dementia" and "CCCAD" as search terms) and the personal knowledge of the authors uncovered seven studies that examined aspects of the CCCAD. In one, the CCCAD recommendations were compared to American recommendations for the differential diagnosis of dementing diseases. ${ }^{44}$ A later report looked at whether participation in the CCCAD influenced conference participants with respect to their recommendations to primary care physicians for the assessment of dementia. ${ }^{45}$ It was found that participants were influenced by the consensus process and did modify their initial positions. The CCCAD recommendations for neuroimaging were evaluated in a Canadian dementia clinic population. ${ }^{46}$ Their results were supportive of the CCCAD opinion that universal CT scanning was not justified. Cheok et $\mathrm{al}^{47}$ examined practice patterns of family physicians for diagnosing and managing dementia patients. Of the twenty family physicians who agreed to participate in the study, only four were aware of the CCCAD recommendations. In correspondence commenting on this study, the principal author of the CCCAD report noted that so few community physicians being aware of the CCCAD was "indeed sobering." 48 An unpublished study by Bell-Irving et $\mathrm{al}^{49}$ examined the awareness of family physicians in British Columbia about the recommendations of the CCCAD. A random sample of 600 of the 1200 physicians registered with the College of Family Physicians of British Columbia were sent a questionnaire. Three hundred and twenty-three (54\%) completed the survey. Their knowledge of the CCCAD recommendations was often deficient - e.g., $53.3 \%$ stated that they routinely performed the suggested screening test for cognition (the MiniMental State Examination); $44.8 \%$ routinely assessed function; and, only $0.9 \%$ could correctly select the recommended laboratory tests. Most $(76.7 \%)$ knew that neuroimaging was not always required. Finally, Frank ${ }^{50}$ reviewed the CCCAD recommendations for laboratory evaluation of dementia and felt they were supported by the available literature.

\section{EVALUATION OF GUIDES TO DEMENTIA CARE}

The observation that consensus statements are not extensively evaluated after production is not unique to the CCCAD. A 
Medline search revealed only two studies which critically evaluated another set of recommendations for the assessment of dementia. The Quality Standard Subcommittee of the American Academy of Neurology published "Practice Parameters for the Evaluation of Dementia" in 1994. Chui and Zhang ${ }^{51}$ examined the usefulness of their recommendations for laboratory studies, neuroimaging and neuropsychology. It was found that laboratory studies influenced management in $12.6 \%$ of subjects. Equivalent figures for neuropsychology and neuroimaging were $1.4 \%$ and $15.1 \%$ respectively. The authors concluded that these practice parameters were a useful first step towards improving the cost effectiveness of the dementia work-up.

The second study found was particularly informative. ${ }^{52}$ An educational strategy was developed to increase neurologists' adherence with six specific suggestions of the above noted practice parameters. A multifaceted educational approach was undertaken consisting of a mailed CME course, a resource manual with tools, an invitation to a seminar, and five reminder mailings. Adherence was improved for three of the six suggestions by the intervention.

\section{DiSSEMINATION AND IMPLEMENTATION OF THE CCCD}

Haynes and colleagues ${ }^{53-56}$ have outlined three steps which should occur for the transfer of research findings into practice. First, one has to get the evidence straight. Research findings have to be balanced with grounded knowledge of the circumstances of practice. Subsequent to this, evidence-based policy (e.g., CPGs) should be developed. Finally this policy is applied by developing a carefully thought out action plan. Factors which would help in dissemination and acceptance should be sought. Key issues influencing the uptake of CPGs are their intrinsic qualities (e.g., simplicity, brevity, local relevance), usefulness and relevance to primary medical care, their source and the degree of support for them from respected quarters. ${ }^{57}$

Changing physician behaviour is a daunting challenge. After primary dissemination, a multi-faceted approach using effective forms of CME is required to promote the adoption of CPGs. The evidence that CPGs truly do improve patient outcomes is weak. The impact of the 1989 CCCAD was likely muted by the absence of an explicit detailed plan for dissemination and implementation.

An explicit dissemination plan for the CCCD was agreed upon by the participants. Eight points in the plan have been fully implemented. The conclusions of the CCCD have been published in journals widely available to Canadian family physicians. ${ }^{1,4,58,59}$ Before dissemination a draft of the recommendations was distributed to a convenience sample of primary care physicians for critical review before they were accepted as final. The following organizations received and have endorsed the recommendations: Alzheimer's Society of Canada; Canadian Academy of Geriatric Psychiatry; Canadian Neurological Society; Canadian Society of Geriatric Medicine (renamed the Canadian Geriatrics Society); College of Family Physicians of Canada; Consortium of Canadian Centres for Clinical Cognitive Research; and, the Société québécoise de gériatrie. Slides were made and sent to all the participants of the Consensus Conference. These slides provided an overview of the CCCD and, its recommendations. The slides have been extensively used by CCCD participants for CME presentations. With the publication of the core paper in the Canadian Medical Association Journal, ${ }^{1}$ a press release was distributed to media outlets across the country. The story was picked up by 15 newspapers (total circulation 1,879,732), three radio stations (listening audience 24,260), and seven television stations (viewing audience 1,544,000). ${ }^{60}$ The recommendations are available on a variety of web pages (e.g., www.cma.ca/cmaj/supplements.htm). It was agreed that the Council of the Consortium of Canadian Centres for Clinical Cognitive Research would assume responsibility for periodic reviews and updates of the statements. The background papers prepared for the Consensus Conference were submitted for peer review and publication in a supplementation of the Canadian Journal of Neurological Sciences.

In preparation for the dissemination of the recommendations, a steering committee of the CCCD prepared and distributed (in collaboration with the College of Family Physicians of Canada) a questionnaire in February of 1999 to a random sample of over 2,000 Canadian family physicians, stratified by region. ${ }^{61}$ Approximately 500 responded. Eighty-eight percent of the respondents treated patients with dementia. Approximately $41 \%$ reported difficulties in assessing patients with dementia and approximately $50 \%$ reported difficulties in managing these patients; and $78.7 \%$ of respondents believed that CPGs on the assessment and management of dementia would be useful to them. The results of this survey indicated that many family physicians are looking for guidelines in this problematic area.

At a provincial and/or university level a good deal of work has been and is being undertaken. Using Alberta as an example, a group at the University of Calgary have put together a MAINPRO-C course for family physicians on "Alzheimer's Disease and other Dementias" based on the CCCD recommendations. MAINPRO-C accreditation criteria requires achieving the highest standard for CME activities. ${ }^{62}$ Learning objectives have to be based on an accurate needs assessment of the specified targeted audience. Most of the learning must occur within small groups. Participants' knowledge/performance are evaluated post-course to provide them with specific feedback on their learning. The dementia course achieved these standards. Two streams (one for those less experienced in the management of dementing illnesses and one for those more experienced) are offered during a full-day course. In collaboration with Pfizer Canada Inc., this course is being disseminated across the country while adhering to the CMA policy on CME. ${ }^{63} \mathrm{Up}$ to the 17 th of June, 2000 a total of 141 family physicians have taken the course. Utilizing the work done for the course, a CCCD-based chart audit tool and a clinical vignette (with questions) have been developed for self-appraisal of a physician's clinical skills in the care of dementia. ${ }^{64}$ The Alberta Clinical Practice Guidelines Program has struck a Cognitive Impairment Working Group which has been charged with the responsibility of developing CPGs on the assessment and management of dementing disorders. The conclusions of the CCCD are being used to direct this effort.

Researchers are encouraged to evaluate the quality and/or impact of the recommendations of the CCCD and any CPGs which may arise from them. The consensus process is not infallible, having a number of limitations.$^{65}$ Different methods of 
promoting implementation should be examined. Dissemination of any research findings arising from these studies are strongly encouraged. We must move beyond the simple production of consensus statements and CPGs. We must optimize their dissemination and implementation if we are going to improve practice patterns and patient outcomes. Evaluation is needed in order to answer the question - Do they make any difference?

\section{REFERENCES}

1. Patterson $\mathrm{C}$, Gauthier S, Bergman $\mathrm{H}$, et al. The recognition, assessment and management of dementing disorders conclusions from the Canadian Consensus Conference on Dementia. Can Med Assoc J 1999; 160 (Suppl 12):S1-S15.

2. Rotondi AJ, Kvetan V, Carlet J, Sibbald WJ. Consensus Conferences in critical care medicine. Crit Care Clin 1997; 13:417-439.

3. Vincent JL, Berré J. An evidence-based approach to round tables and consensus conferences. Crit Care Clin 1998, 14:539-547.

4. Patterson CJS, Gauthier S, Bergman H, et al. Canadian Consensus Conference on Dementia - a physician's guide to using the recommendations. Can Med Assoc J 1999; 160:1738-1742.

5. Cook DJ, Greengold NL, Elhodt AG, Weingarten SR. The relation between systematic reviews and practice guidelines. Ann Intern Med 1997; 127:210-216.

6. Littlejohns P, Cluzeau F, Bale R, et al. The quantity and quality of clinical practice guidelines for the management of depression in primary care in the UK. Br J Gen Pract 1999; 49:205-210.

7. Audet AM, Greenfield S, et al. Medical practice guidelines - current activities and future directions. Ann Intern Med 1990; 113:709714.

8. Marder RJ. Relationship of clinical indicators and practice guidelines. QRB Qual Rev Bull 1990; 16(2):60.

9. Directory of Canadian clinical practice guidelines. Canadian Medical Association (Ottawa), 1994

10. James PA, Cowan TM, Graham RP, Majeroni BA. Family physicians'attitudes about and use of clinical practice guidelines. J Fam Pract 1997; 45:341-347.

11. Harrigan ML. Quality of care-issues and challenges in the '90s. Canadian Medical Association (Ottawa), 1992;67-89.

12. Hayward RSA, Guyatt GH, Moore KA, et al. Canadian physicians' attitudes about and preferences regarding clinical practice guidelines. Can Med Assoc J 1997; 156:1715-1723.

13. Buske L. Impact of CPGs growing. Can Med Assoc J 1998, 159:1336.

14. Implementing clinical practice guidelines - a handbook for practitioners. Canadian Medical Association, 1997.

15. Davis DA, Taylor-Vaisey A. Translating guidelines into practice. Can Med Assoc J 1997; 157:408-416.

16. Freemantle N, Harvey EL, Wolf F, et al. Printed educational materials to improve the behaviour of health care professionals and patient outcomes. In: Bero L, Grilli R, Grimshaw J, Oxman A (eds). Collaboration on Effective Professional Practice Module of The Cochrane Database of Systematic Reviews. The Cochrane Collaboration; Issue 4. Oxford: Update Software; 1997.

17. Thomson MA, Oxman AD, Davis DA, et al. Outreach visits to improve health professional practice and health care outcomes. In: Bero L, Grilli R, Grimshaw J, Oxman A (eds.): Collaboration on Effective Professional Practice Module of The Cochrane Database of Systematic Reviews. The Cochrane Collaboration; Issue 4. Oxford: Update Software; 1997.

18. Thomson MA, Oxman AD, Haynes RB, et al. Local opinion leaders to improve health professional practice and health care outcomes. In: Bero, Grilli R, Grimshaw J, Oxman A (eds): Collaboration on Effective Professional Practice Module of The Cochrane Database of Systematic Reviews. The Cochrane Collaboration; Issue 4. Oxford: Update Software; 1997.

19. Shea S, DuMouchel W, Bahamonde L. A meta-analysis of 16 randomized controlled trials to evaluate computer-based clinical reminder systems for preventive care in the ambulatory setting. $\mathrm{J}$ Am Med Inform Assoc 1996; 3:399-409.
20. Balas EA, Boren SA, Brown GD, et al. Effect of physician profiling on utilization - a meta-analysis of randomized clinical trials. J Gen Intern Med 1996; 11:584-590.

21. Haynes RB, Davis DA, McKibbon A, Tugwell P. A critical appraisal of the efficacy of continuing medical education. JAMA 1984; 251:61-64.

22. Davis DA, Thompson MA, Oxman AD, Haynes RB. Evidence for the effectiveness of $\mathrm{CME}$ - a review of 50 randomized controlled trials. JAMA1992; 268:1111-1117.

23. Davis DA, Thomson MA, Oxman AD, Haynes RB. Changing physician performance - a systematic review of the effect of continuing medical education strategies. JAMA 1995; 274:700705.

24. Oxman AD, Thomson MA, Davis DA, Haynes RB. No magic bullets - a systematic review of 102 trials of interventions to improve professional practice. Can Med Assoc J 1995; 153:14231431.

25. Davis D, O'Brien MAT, Freemantle N, et al. Impact of Formal Continuing Medical Education. JAMA1999; 282:867-874.

26. Browman GP, Levine MN, Mohide EA, et al. The practice guidelines development cycle - a conceptual tool for practice guidelines development and implementation. J Clin Oncol 1995; 13:502-512.

27. Rush J. Clinical practice guidelines - good news, bad news, or no news? Arch Gen Psychiatry 1993; 50:483-490.

28. Kelly JT, Toepp MC. Practice parameters - development evaluation dissemination, and implementation. QRB Qual Rev Bull 1992; 18:405-409.

29. Brennan PJ, Abrutyn E. Developing policies and guidelines. Infect Control Hosp Epidemiol 1995; 16:512-517.

30. Hayward R, Laupacis A. Initiating, conducting and maintaining guideline development programs. Can Med Assoc J 1993; 148:507-512.

31. Wortman PM, Smyth JM, Langenbrunner JC, Yeaton WH. Consensus among experts and research synthesis - a comparison of methods. Int J Technol Assess Health Care 1998; 14(1):109122.

32. Dunn EV, Norton PG, Stewart M, Tudiver F, Bass MJ (eds). Disseminating research/changing practice - Research Methods for Primary Care, Volume 6. Thousand Oaks: Sage Publications. 1994.

33. Fox RD, Mazmamian PE, Putnam RW (eds). Change and learning in the lives of physicians. New York: Praeger. 1989.

34. Kinkman MS. Competing demands in psychosocial care. Gen Hosp Psychiatry 1997; 19:98-111.

35. Fox RD, Bennett NL. Learning and change-implications for continuing medical education. BMJ 1998; 316(7129): 466-468.

36. Karuza J, Calkins E, Feather J, et al. Enhancing physician adoption of practice guidelines - dissemination of influenza vaccination guideline using a small-group consensus process. Arch Intern Med 1995; 155:625-632.

37. Worrall G, Chaulk P, Freake D. The effects of clinical practice guidelines on patient outcomes in primary care - a systematic review. Can Med Assoc J 1997; 156:1705-1712.

38. Hayward RSA. Clinical practice guidelines on trial. Can Med Assoc J 1997; 156:1725-1727.

39. Cabana MD, Rand CS, Powe NR, et al. Why don't physicians follow clinical practice guidelines? JAMA1999; 282:1458-1465.

40. Basinski AS. Evaluation of clinical practice guidelines. Can Med Assoc J 1995; 153:1575-1581.

41. Organizing Committee, Canadian Consensus Conference on the Assessment of Dementia. Assessing dementia - the Canadian consensus. Can Med Assoc J 1991; 144:851-853.

42. Clarfield AM (Principal Author). Canadian Consensus Conference on the Assessment of Dementia (5-6 October 1989). Canadian Consensus Conference of the Assessment of Dementia (Montreal), 1991.

43. Feightner JW, Gass DA, Bass MJ. An approach to assessing dementia. Can Fam Physician 1992; 38:2347-2353.

44. Clarfield AM, Foley JM. The American and Canadian consensus conferences on dementia - is there consensus? J Am Geriatr Soc 1993; 41: 883-886. 
45. Clarfield AM, Kogan S, Bergman $\mathrm{H}$, et al. Do consensus conferences influence their participants? Can Med Assoc J 1996; 154:331-336.

46. Freter S, Bergman H, Gold S, Chertkow H, Clarfield AM. Prevalence of potentially reversible dementias and actual reversibility in a memory clinic cohort. Can Med Assoc J 1998; 159:657-662.

47. Cheok AS, Cohen CA, Zucchero CA. Diagnosing and managing dementia patients. Can Fam Physician 1997; 43:477-482.

48. Clarfield AM. Canadian Consensus Conference on the Assessment of Dementia reports. (letter). Can Fam Physician 1997; 43:1343.

49. Bell-Irving KA, Donnelly M, Berkowitz J. Effective dementia management and the family physician - the family physician's perspective. (Personal Communication).

50. Frank C. Dementia workup - deciding on laboratory testing for the elderly. Can Fam Physician 1998; 44: 1489-1495.

51. Chiu H, Zhang Q. Evaluation of dementia - a systematic study of the usefulness of the American Academy of Neurology's Practice Parameters. Neurology 1997; 49:925-935.

52. Gifford DR, Holloway RG, Frankel MR, et al. Improving adherence to dementia guidelines through education and opinion leaders. Ann Intern Med 1999; 131:237-246.

53. Haynes RB, Sackett DL, Gray JAM, Cook DJ, Guyatt GH. Transferring evidence from research into practice -1 . The role of clinical care research evidence in clinical decisions. ACP J Club 1996; 125:A14-A16.

54. Haynes RB, Sackett DL, Gray JAM, Cook DL, Guyatt GH. Transferring evidence from research into practice -2 . Getting the evidence straight. ACPJ Club 1997; 126:A14-A16.

55. Gray JAM, Haynes RB, Sackett DL, Cook DJ, Guyatt GH.
Transferring evidence from research into practice -3 . Developing evidence-based clinical policy. ACPJ Club 1997; 126:A14-A16.

56. Haynes RB, Sackett DL, Guyatt GH, Cook DJ, Gray JAM. Transferring evidence from research into practice -4 . Overcoming barriers to application. ACPJ Club 1997; 126:A14-A15.

57. Langley C, Faulkner A, Watkins C, Gray S, Harvey I. Use of guidelines in primary care - practitioners' perspectives. Fam Pract 1998; 15:105-111.

58. Wetmore S, Feightner J, Gass D. Worrall G. Canadian Consensus Conference on Dementia - Summary of the Issues and Key Recommendations. Can Fam Physician 1999; 45:2136-40, 2143, 2154-9.

59. Patterson CJS on behalf of the Steering Committee for the CCCD. Can we improve primary medical care of people with dementia? Mature Medicine 1999; 219-222

60. National PharmaCom. Press Report (July 27, 1999).

61. Patterson C, Castillo C, Hogan D. Dementia - Practice Patterns and Continuing Education Preferences of Canadian Family Physicians. A National Survey. Clin Invest Med 1999; 22(4 Suppl):S18.

62. The College of Family Physicians of Canada. MainPRO guidelines and requirements. The College of Family Physicians of Canada, July/1995.

63. Physicians and the Pharmaceutical Industry (Update 1994). Can Med Assoc J 1994; 150:256A-256C

64. Hogan DB, Pereles L, Lebeuf C, Wright B. Assessment and management of dementia - Self-assessment of clinical skills. Can J CME 2000;112(9):105-117.

65. Sniderman AD. Clinical trials, consensus conferences, and clinical practice. Lancet 1999; 354:327-330. 